\title{
Are We Paying Enough Attention to Clarifying Our Vision for Master's-Prepared Nurses and Ensuring That Educational Programs and Workplaces Are Prepared to Help Achieve That Vision? An Invitation to Engage in an Important Conversation
}

\author{
Gail J. Donner, RN, PhD \\ Lawrence S. Bloomberg Faculty of Nursing \\ University of Toronto \\ Partner, donnerwheeler, Career Consultants \\ Janice Waddell, RN, PhD \\ Associate Dean \\ Faculty of Community Services \\ Associate Professor \\ Daphne Cockwell School of Nursing \\ Ryerson University \\ Senior Associate, donnerwheeler, Career Consultants
}

Nursing education and nursing practice are on the move, and at least some of our progress in recent years must be credited to the increasing numbers of nurses with baccalaureate, master's and doctoral degrees. A baccalaureate degree is the status quo now in most of the country and, even where progress is slow, we are past the tipping point. This is great and what we said we wanted - to increase the educational preparation of nurses in order to improve patient care and to contribute to scholarship and leadership. As this change unfolds, our challenge is to think about whether we will simply drift into a future where we have large numbers of graduate prepared nurses entering an established workforce, or whether we will proactively design a future that will maximize the potential of those nurses to improve quality of patient care and participate in leading the system change we all say is needed. As these nurses enter or re-enter the workforce, we need to ensure they have work that is satisfying to them and relevant to the needs of patients, clients and the system. Will we respond to the challenges with strategies and actions that maximize job 
satisfaction and ensure career and job retention for the master's-prepared nurse, and that support healthcare settings to optimize the integration of this group of nurses into the workplace, or will we risk diminishing the promise of a valuable workforce?

We therefore invite you to engage with us and others in a conversation about the needs of healthcare organizations and master's-prepared graduates as they transition into the workplace. We have some questions for you to consider, but we know that you will have more ideas and will bring your creativity to bear on this discussion about nursing's future.

While the baccalaureate as entry to practice has preoccupied the profession for over 50 years, it seems that in our determination to establish it as the entry credential, we have not given enough time to considering many of its implications. Specifically, we did not appreciate fully enough the large and important impact on education and practice that tens of thousands of baccalaureate-prepared nurses would or could have. One of the results of entry to practice has been the increasing demand for graduate education. So now in Canada we have many master's programs - a good thing - and a large number of nurses enrolled or seeking enrolment in those programs - also a good thing. The Canadian Institute for Health Information (2010) reported that in 2009 the total $\mathrm{RN}$ workforce in Canada was 266,341, of which 8,576 were master's/doctorally prepared (3.0\%), 97,651 (38.0\%) had a baccalaureate degree and 160,111 (59.1\%) were diploma prepared. Although these numbers are not dramatically different from what they have been, it is the future growth that concerns us. The Canadian Nurses Association and Canadian Association of Schools of Nursing (2008) reported that in 2006 (the most recent data they report), there were 946 nurses admitted to master's programs, up from 719 in 2001. In 2007, there were 603 graduates from Canadian master's programs, up from 303 in 2001.

We are concerned that our graduate program planning and curriculum development are based on a possibly erroneous assumption that all students enter graduate studies with a specific career goal or to assume a particular position. A significant number of students may not have specific goals and may be looking to their program to assist them in defining a future role in order to be able to approach their practice as a master's-prepared nurse with intention and confidence. Nurses actually decide to apply to graduate studies for a number of reasons. Some are very clear on how graduate education would help them reach well-thought-out career goals. These students research graduate programs with an eye to assessing the degree to which specific programs will help them achieve the outcomes relevant to their unique goals. Other students see graduate education as a means of opening doors to a range of career opportunities, but do not have particular doors in mind. More recently, nurses have been seeking admission to graduate studies because they have lost their jobs and see going back to school as an alternative to being unemployed. 
Why nurses choose to pursue graduate education may have implications for graduate programs and for employers. Students who come to graduate studies with a clear career path in mind are in a position to shape their participation in the program in a strategic and intentional way. They have a sense of how to utilize their graduate degree to advance their current practice in their current workplace - or to seek a position wherein they can fully utilize their graduate preparation. Students who do not have a sense of how graduate studies will affect their career path may successfully complete their program but then struggle with establishing themselves and using their advanced knowledge within the workplace. This inability or lack of knowledge about how to find one's place in the profession, the workplace and the system could have an important impact on job satisfaction and career retention.

One recent graduate's comment reflects the uncertainty that some master's students may experience at the point of entry to their graduate program:

I applied to grad studies when I lost my full-time job due to layoffs. I was a new BScN grad and knew that my chances of getting another full-time job were slim, so decided that it was as good a time as any to apply to a master's program. I wasn't sure exactly what the program would be like and I didn't really have a plan, so I took my core courses and the electives that seemed interesting. To be honest, I wasn't quite sure what kind of job to apply for when I graduated, so basically just looked for positions that required a graduate degree in nursing.

Healthcare organizations may or may not have established pathways for supporting and engaging master's-prepared graduates. Employers, as well as academics, may be working from a faulty assumption that graduate-prepared nurses arrive at the workplace confident in their ability to articulate and apply their advanced educational preparation in their professional practice. A further comment from the same master's graduate speaks to this concern:

The first job to come up in my organization was a nurse educator role. I wasn't sure if I should apply, since I didn't take any education courses in my program, but decided to give it a try and ended up getting the job. I found the role very difficult - I think they assumed that I would know exactly what to do, and I guess I thought that given I had done well in my program, I should be able to handle it. I was the only educator for my area and felt like a total failure. I stuck with it for six months and then applied to teach at a community college. At least here I have some support to help me develop my teaching skills. I miss direct care, but because I'm not an NP and I don't have a lot of practice experience under my belt, I'm not sure how my graduate preparation would position me to get a job in the clinical area. 
Although some of the challenges concerning integrating master's-prepared graduates are the same ones we faced with baccalaureate-prepared nurses, it does not seem as if we have learned enough from that experience. Have we been working closely enough with new graduates, clinical practice nurses, managers, health professional colleagues and organizations to establish a shared understanding of the shift in curriculum content, teaching methodologies and outcomes of graduate nursing education? This lack of attention to helping the healthcare system at large to understand the master's-prepared nurse may create confusion and unrealistic expectations and, consequently, may diminish the positive integration of new master's-prepared graduates into the workplace and the workforce. Given that we need all our nurses to provide care, leadership and scholarship in healthcare today and in the future, we cannot risk losing any of them because we have failed to provide them with the help and support they need - particularly in their transition to new professional roles within the world of work.

Nursing is an interpersonal activity; it is about being with, planning with and doing with our clients/patients and with other members of the healthcare team. Nursing education and the work environment must respond to nurses just as we aspire to respond to the public - individually - in a nurse-centred way, recognizing that each nurse is an individual with specific needs, wants and abilities. Yes, we have lots of nurses, and individualizing education and work is difficult, but surely we can do better than we have been doing.

We have more questions than answers, and what we think is needed is a no-holdsbarred dialogue among educators, new master's graduates and the field that addresses the following questions:

- Do we know enough about who these new master's graduates are, and do we have the creativity, commitment and energy to learn about and address their needs?

- What do master's-prepared graduates expect from us, from their nursing colleagues or other health professionals, and from nursing leaders?

- Have we responded adequately to the diversity among the nursing student body today, that is, to those with other work experiences or those with already developed goals for their nursing futures?

- Have organizations, nursing colleagues and other healthcare professionals been helped to understand what they might expect from a diverse group of master'sprepared nurses?

- Do educators in both academic and practice settings have specific strategies for assisting in the transition from graduate student to practitioner that recognize the broad range of graduate expectations, the needs of the practice setting, but also the variety of roles that nurses can and will play, especially in the future?

- Would funded programs similar to the New Graduate Initiative in Ontario 
provide both organizations and new master's-prepared nurses with the support needed to integrate and assimilate them successfully into the workplace?

- Would establishing teaching units with a focus on integrating new master's graduates into practice settings create a teaching/learning environment that would serve to optimize the individual and collective potential of this new workforce?

What do you, whether employer, educator, practitioner, or student, think?

Can we talk?

\section{Acknowledgements}

We want to thank Dianne Foster Kent and Mary Wheeler for their support and encouragement and Barbara Bauer for her editorial assistance with the manuscript.

Correspondence may be addressed to: Janice Waddell, Faculty of Community Services, Ryerson University at jwaddell@gwemail.ryerson.ca.

\section{References}

Canadian Institute for Health Information (CIHI). 2010. Registered Nurses: Canadian Trends, 2005-2009. Ottawa: Author. Retrieved May 12, 2011.<http://secure.cihi.ca/cihiweb/products/nursing_report_2005-2009_en.pdf>.

Canadian Nurses Association (CNA) and Canadian Association of Schools of Nursing (CASN). 2008. Nursing Education in Canada Statistics. Ottawa: Author. Retrieved May 12, 2011. <http://www. casn.ca/vm/newvisual/attachments/856/Media/Nursingstats.pdf $>$. 